\title{
Da dimensão pessoal na formação inicial de professores*
}

\section{From initial training: humanization of the formative} processes

\section{De la dimensión personal en la formación inicial de profesores}

\author{
Laura Noemi Chaluh**
}

DOI: http://dx.doi.org/10.20435/serie-estudos.v22i44.964

\begin{abstract}
Resumo
O presente trabalho apresenta resultados produzidos a partir de uma pesquisa que objetivou analisar e compreender os processos formativos desencadeados por um grupo de graduandos do curso de Pedagogia, de uma universidade do interior do estado de São Paulo, no contexto de um projeto de extensão. A perspectiva de formação, sustentada na trilogia linguagem-coletividade-empoderamento, legitima a produção coletiva do conhecimento em um espaço de diálogo e escuta que valoriza a autoria desses futuros professores. Socializo aqui uma proposta na qual foi possível perceber os valores e a intimidade construída no grupo, o reconhecimento do outros, a proximidade, o falar, o escutar, o olhar solidário. Uma proposta de formação que mostra a importância de resgatar a dimensão pessoal da profissão docente. Uma formação que legitima uma atenção e cuidado nas relações instituídas no contexto escolar, deixando em evidência que a formação docente não se constitui apenas por aspectos técnicos e científicos. O reconhecimento da subjetividade nos processos formativos talvez seja um diferencial na qualidade de educação que tanto almejamos.
\end{abstract}

\section{Palavras-chave}

Formação inicial; diálogo; escuta; Pedagogia.

\begin{abstract}
In this work, I share results produced in a survey that aims to analyze and understand the formative processes triggered by a group of undergraduate students of Pedagogy, in a University located in the interior of the State of Sao Paulo, in the context of an extension project. The formative perspective is sustained in the trilogy language-community-empowerment legitimizing the collective production of knowledge in a space of dialogue and listening that values the authorship of these future teachers. I share here a proposal in which it was possible to see the values and nearness built in the group, the

\footnotetext{
* O artigo, no seu conteúdo e forma, inspira-se em trabalho apresentado no III Congresso Internacional de Avaliação e VIII Congresso Internacional de Educação com o título "Processos formativos e qualidade: escuta e diálogo na formação inicial”, 2014.

** Universidade Estadual Paulista “Júlio de Mesquita Filho" (UNESP), Rio Claro, São Paulo, Brasil.
} 
recognition of others, proximity, speaking, listening formative, the supportive look. A proposal for formation that shows the importance of rescuing humanity in the formative processes, $A$ formation that legitimates attention and care in the relations present in the school context, enhancing the evidence that teacher training goes beyond technical and scientific aspect. The recognition of subjectivity in the formation processes may be a plus in the education quality that we hope to achieve.

\section{Key words}

Initial training; dialogue; listening; Pedagogy.

\section{Resumen}

El presente trabajo presenta resultados producidos a partir de una investigación que tuvo como objetivo analizar y comprender los procesos formativos desenvueltos por un grupo de graduados del curso de Pedagogía, de una universidad del interior del estado de San Pablo, en el contexto de un proyecto de extensión. La perspectiva de formación, sustentada en una trilogía lenguaje-colectividad-empoderamento, legitima la producción colectiva del conocimiento en un espacio de diálogo e escucha que valoriza la autoría de esos futuros profesores. Socializo acá una propuesta en la cual fue posible percibir los valores y la intimidad construida en el grupo, el reconocimiento de los otros, la proximidad, el hablar, el escuchar, la mirada solidaria. Una propuesta de formación que muestra la importancia de rescatar la dimensión personal de la profesión docente. Una formación que legitima una atención y cuidado en las relaciones instituidas en el contexto escolar, dejando en evidencia que la formación docente no se constituye apenas por aspectos técnicos y científicos. El reconocimiento de la subjetividad en los procesos formativos tal vez sea un diferencian en la calidad de la educación que tanto deseamos.

\section{Palabras clave}

Formación inicial; diálogo; escucha; Pedagogía.

\section{INTRODUÇÃO}

Neste trabalho, socializo alguns resultados produzidos a partir de uma pesquisa ${ }^{1}$ que objetiva compreender os processos formativos desencadeados em um grupo de alunos de um curso de Pedagogia de uma universidade pública do interior do estado de São Paulo (Brasil) e que participam de um projeto de exten-

${ }^{1}$ Trabalho vinculado ao projeto de pesquisa "Entrelaçando cultura: formação, linguagem, coletividade, empoderamento" que conta com o auxílio da FAPESP (Número do processo: 2012/00854-7) e CNPq (Número do Processo: 408739/2013-4). são, o qual coordeno e que iniciou suas atividades no ano de 2010. O projeto enfatiza a formação de futuros professores, articulada com a pesquisa, na busca por entrelaçar a cultura escolar e a cultura acadêmica. Nesse contexto, procuramos considerar o cotidiano escolar como espaço formativo e como objeto de estudo e refletir sobre a organização do trabalho pedagógico na escola. Essas ações estão atreladas a outros dois espaços de formação dos quais esses alunos também participam: um projeto de pesquisa e intervenção, desenvolvido em escolas de Ensino Fundamental I, e um curso de extensão, oferecido para coordenadores 
pedagógicos e vice-diretores da rede municipal de ensino da cidade onde a universidade está localizada. Isso possibilita aos alunos vivenciar a complexidade da escola e seus atravessamentos.

A pesquisa, de orientação sócio-histórica (FREITAS, 2003; AMORIM, 2004), perspectiva dialógica, considera pesquisa como uma relação entre sujeitos, na qual a interação assume um papel fundamental na constituição das subjetividades. Nesse sentido, o critério desta pesquisa é a participação tanto do investigador quanto do investigado; pesquisador e pesquisado refletem, aprendem e ressignificam-se no processo de pesquisa. Assim, sou pesquisadora do projeto de extensão que eu mesma coordeno, o que implica pesquisar a minha própria prática como formadora.

Como professora formadora de futuros professores, várias questões me preocupavam e foram estas as que me levaram a delinear a proposta do referido projeto de extensão. Uma questão central era definir quais as práticas pedagógicas que, atentas ao outro, possibilitam educar um olhar e uma escuta?

Neste trabalho problematizo, a partir das escritas produzidas pelos alunos e por mim, as implicações que teve a leitura e discussão do texto "Segredos do coração: a escola como espaço para o olhar sensível" (KOLB-BERNARDES, 2010). Essa leitura foi uma inspiração para nós, já que contribui para pensar nos "nossos segredos do coração", e nos levou a fazer uma proposição: sair da sala de aula para termos um encontro no bambuzal, no qual foi possível perceber a intimidade construída entre nós, uma vez que neste redescobrimos que os outros também somos nós.

Esse encontro legitimou a importância dos valores construídos enquanto grupo e que ficaram registrados nas escritas produzidas pelos alunos após o encontro: o outro, a proximidade, o falar, o escutar, o olhar solidário. Assim, socializo uma proposta de formação que mostra a importância de resgatar a humanidade nos processos formativos, pois talvez seja esta a qualidade de educação que tanto almejamos.

Considero que socializar essa experiência pode deixar em evidência uma forma de pensar e de fazer a prática pedagógica. Por esse motivo, problematizo aqui de que forma as práticas de formação instituídas no contexto desse projeto podem sinalizar para os formadores de futuros professores duas questões: a) a necessidade de estarmos atentos ao que acontece nos encontros com nossos alunos, e b) quais os saberes pedagógicos que necessitamos para que, de fato, possamos promover uma formação que tenha como sustento a formação integral dos professores em formação.

Essa proposta também mostra o caminhar da professora, que, atenta aos outros, os participantes do projeto de extensão, conseguiu delinear algumas proposições. Professora que no caminhar percebe que a "pedagogia de experiência" sustenta e legitima outra forma de produzir um saber, um saber que surge dos acontecimentos vividos. 
Para isso, dialogo com Contreras Domingo (2010) já que o autor pensa numa "pedagogia da experiência" e explicita com clareza algumas das minhas inquietações:

Necesito un saber pedagógico que más que decirme qué hacer, me prepare para estar atento, para estar a la escucha y para plantearme todas las preguntas mientras hago; por lo tanto, no me dice qué hacer, pero requiere de mí un hacer que no tape, que no impida, que no me dificulte esta escucha atenta e este interrogarme. Paradójicamente, un saber que aunque no me dice qué hacer, me coloca en una dirección para ello, para un hacer que requiere generar nuestro hacer en el propio hacer. (CONTRERAS DOMINGO, 2010, p. 248).

Contreras Domingo (2010) traz uma discussão que me interessa, traz um paradoxo: como apreender um saber que não me diz o que fazer e que, pelo contrário, é um saber que me coloca em uma posição de abertura e legitimidade por aquilo que gera o nosso próprio fazer? Assim, o autor explicita a necessidade de reconhecer que, no momento de nosso fazer, é que geramos o nosso próprio fazer e vamos tomando decisões a respeito de nossas ações.

Socializo aqui uma proposta de formação que mostra de que forma aprendi no meu próprio fazer a importância de resgatar a nossa humanidade nas práticas pedagógicas que instituímos nos contextos formativos. Esse fazer com os alunos do projeto de extensão indiciam que é um fazer atento ao princípio da escuta, já que isso possibilita estarmos atentos aos outros. Assim, mostro uma proposta de formação que, ao estar atenta aos outros, sinaliza a necessidade de estarmos implicados em uma "pedagogia da experiência", uma pedagogia que se constrói no mesmo momento em que se faz.

\section{O PROJETO DE EXTENSÃO: CONTEXTUALIZAÇÃO}

O referido projeto, com reuniões semanais, pauta-se em uma concepção de formação que tem como princípios: a dimensão da pesquisa; a centralidade da linguagem (oral e/ou escrita) e da interlocução; o reconhecimento dos outros e da coletividade e o empoderamento através da palavra. Assim, a perspectiva de formação assumida por mim enquanto coordenadora do referido projeto está atrelada à trilogia linguagem-coletividade-empoderamento (CHALUH, 2011a; 2011b; 2012). Uma trilogia que me ajuda a repensar meu fazer docente: uma formação inicial da qual os alunos se sintam partícipes na/da construção do conhecimento, um conhecimento construído no coletivo, em um espaço de diálogo e escuta que valoriza a autoria desses futuros professores. Um fazer docente que legitima a prática da oralidade e escuta, colocando a produção/escrita de textos como aspectos que deveriam perpassar o currículo dos cursos de Licenciatura.

O referido projeto de extensão, 
intitulado "Grupo de Formação: Diálogo e Alteridade" busca favorecer o diálogo e a interlocução para estudar, pesquisar e escrever acerca da prática pedagógica. Como já referido, articula-se a um projeto de pesquisa e intervenção desenvolvido em escolas do município e a um curso de extensão para educadores da mesma rede. Nos encontros semanais do projeto, são socializadas as experiências vividas com os educadores nesses dois âmbitos e, a partir de leitura de textos cujas temáticas surgem no diálogo com os alunos, procuramos buscar embasamento teórico para as nossas discussões e ações no contexto escolar. Temos, ainda, a intencionalidade de sistematizar o conhecimento a partir da prática da escrita na busca por legitimar os saberes construídos pelos graduandos e de definir propostas de trabalho colaborativo com os professores nas escolas. Nesse sentido, desde 2010, temos instituído a prática de registrar por escrito o que acontece nos nossos encontros semanais, em um caderno coletivo do grupo. No ano de 2011, instituímos o projeto "Cartas pra nós" (CHALUH, 2011b), no qual cada um de nós escrevia mensalmente uma carta para o grupo tendo como objetivo prolongar nosso diálogo; as cartas eram socializadas por e-mail e posteriormente discutidas. No ano de 2012, instituímos como prática de escrita as "Escritas após aula". Essas escritas buscavam responder a três perguntas: $O$ que vês? O que pensas? O que fazes com o que pensas? São perguntas inspiradas no livro de Rancière (2002) "O mestre
Ignorante: cinco lições sobre a emancipação intelectual". E ainda, nesse mesmo ano, foi promovida a escrita de Pipocas Pedagógicas (CAMPOS; PRADO, 2013), que são crônicas de acontecimentos vividos no contexto escolar. No ano de 2013, os alunos explicitaram a necessidade de uma escrita mensal que tivesse relação com alguma temática que os tenha envolvido a partir dos encontros semanais.

Destaco que todas as escritas são socializadas e que o movimento de valorização da prática de escrita é uma instância que a cada dia se apresenta com mais potencialidade, afirmo isso pelas reflexões que, por meio dos escritos, fazem cada um dos participantes do projeto de extensão.

\section{DE COMO O TEXTO NOS PROVOCOU...}

A autora do referido texto (KOLBBERNARDES, 2010) narra algumas propostas desenvolvidas com crianças entre 8 e 10 anos, enquanto professora de uma escola pública do ensino fundamental, na cidade de Belo Horizonte, durante as aulas de arte no ano de 2005. A partir da experiência vivida no início desse ano letivo, com a perda de um professor da escola onde ela estava inserida, se questionou:

[...] poderia a escola ser um lugar para o acolhimento de histórias e memórias daqueles que a frequentam? Seria possível trabalhar o sentimento de perda, cultivar segredos, sonhos e desejos na escola? 
Seria possível, pois, através da atividade artística, construir um olhar e um fazer sensíveis para as histórias de cada um? (KOLB-BERNARDES, 2010, p. 74).

A preocupação da professora era o de garantir na escola um tempo para que os alunos socializassem suas narrativas, que não necessariamente teriam que vir pela escrita. Por esse motivo, a professora optou pela utilização de outras formas de conhecer e dar significado às memórias e às histórias dos seus alunos: desenhos, fotos, diários, caixas contendo objetos que traziam memórias e histórias.

A organização do trabalho pedagógico no contexto das aulas de arte foi pensada tendo como intencionalidade que esses encontros fossem uma oportunidade para os alunos

[...] recontarem sua história, reconstruírem seu passado e construírem sua identidade por meio de variados fazeres, onde a palavra une-se a outras materialidades. Nessa abordagem, o trabalho de arte foi repensado, buscando dialogar com a cultura local e com outras manifestações culturais brasileiras. (KOLBBERNARDES, 2010, p. 73).

Assim, foi constituído um ambiente no qual a memória, as histórias dos alunos fossem legitimadas, tanto a história pessoal como a história local.

Dentre as propostas elaboradas pela professora, foi feita a leitura do livro "Guilherme Augusto Araújo
Fernandes" (FOX, 1995) e outras atividades que articulavam experiências pessoais com as

[...] culturas africana e indígena e com a tradição das bordadeiras mineiras, que tecem a sua história de vida com fios e panos. Ficou explicitamente visível como essa experiência de memória, de desejos, de segredos se tornou mais intensa quando tivemos o contato com a lenda Quarup dos índios Kamaiurá (Xingu), com o fazer dos patuás da tradição africana e com os bordados da Família Dumont e das Mariquinhas. Constituindo o núcleo do projeto elaborado, tais situações e atividades planejadas nos conduziram a universos diferenciados, ampliando o repertório dos alunos, provocando não apenas o pensamento, mas o sentimento, articulando-os intensamente em novos fazeres. (KOLB-BERNARDES, 2010, p. 76).

A seguir apresento o registro elaborado por Letícia no dia em que fizemos a leitura do referido texto; nesse dia, ela foi responsável por produzir o registro semanal, uma prática instituída no grupo.

Iniciamos a reunião com a leitura do registro de Mariana, cada palavra nos fazia voltar a uma semana em nosso passado, em nossa história.

Contei para o grupo sobre 
minha experiência na escola [nome da escola], e do projeto "Cada um tem sua história", que propus para a turma. Do quanto fiquei admirada ao ver como as coisas estão em sintonia em minha vida, a ligação entre o projeto e a leitura proposta para hoje - Segredos do Coração: A Escola Como Espaço Para O Olhar Sensível de Bernardes [...].

Em seguida assistimos a dois vídeos das Mariquinhas, moradoras da periferia de Belo Horizonte, que bordaram suas histórias de vida e de sofrimento. O texto cita uma visita das crianças à exposição dos trabalhos das bordadeiras [...]. (Caderno coletivo. Letícia2 ${ }^{2}$. Registro do dia 15 de maio de 2012).

Nesse encontro, foi legitimada a importância de, na escola, levar em consideração as histórias de vida, tivemos a possibilidade de assistir ao trabalho das Mariquinhas que bordam suas histórias, trabalho que conhecemos a partir do texto de Kolb-Bernardes (2010).

Mas foi só no mês de agosto, quando os alunos do projeto de extensão colocaram a necessidade de olhar, também, para nossas próprias histórias. Segue registro do caderno coletivo, pelo qual Juliane foi responsável:

${ }^{2}$ Meu agradecimento aos alunos citados, que me autorizaram a socializar suas falas.
Joseano aproveitou para contar sobre o projeto da professora que ele acompanha, que promoveu um encontro com todos os alunos da mesma série, juntamente com os professores, para contarem suas histórias de vida. Para começar ela colocou a música "Como uma onda no mar" do Lulu Santos, e contou sua história. Com isso, os alunos se emocionaram e duas alunas resolveram dividir com os colegas suas histórias marcantes, que mexeu até com os professores. A professora Laura ressaltou a importância de conhecer e reconhecer $o$ outro, como um ser humano, que também tem sua história, e como isso é importante no ambiente escolar. [...]

Para terminar, a Raquel deu a ideia de que nós também contássemos nossas histórias, trazendo uma foto ou objeto marcante. Todos gostaram da ideia, mas ainda não definimos uma data" (Caderno coletivo. Juliane. Registro do dia 9 de agosto de 2012; grifos meus).

Foi assim que, olhando para a necessidade de contar nossas histórias no âmbito da universidade, decidimos marcar o nosso encontro no bambuzal, um "piquenique acadêmico" regado de fotos para compartilhar e histórias para contar. Uma necessidade sinalizada pelo grupo, que, em vários momentos, apon- 
tava a necessidade de marcar encontros em outros contextos e de aprofundar a nossa intimidade como grupo.

\section{O ENCONTRO NO BAMBUZAL...}

Foi um dia ensolarado. Céu azul, um violão para ouvir músicas, fotos nas mãos, câmera para registrar o nosso encontro no bambuzal...

A seguir trago as falas registradas após o encontro e nas quais é possível perceber a necessidade de saber do outro, do reconhecimento do outro, de escutar, de olhar, de reconhecermos para além de "alunos" e "professoras", a humanidade que permeou o nosso encontro. Trago o registro elaborado por Dani, responsável por relatar esse encontro.

Primeiro encontro ao ar livre. $E$ livre de fato nos sentimos. [...]

Chegando lá nos deparamos com uma paisagem incrível do horto florestal, um céu azul anil que nos cobria e um vento que ao nos tocar dava uma sensação de liberdade de vida (pelo menos eu tive esse sentimento). Estendemos nossas toalhas e colocamos os lanches no meio. Joseano nos contou que estava "quebrado" por causa do estágio na creche, ficou admirado pela quantidade de trabalho que as professoras, monitoras e cozinheiras tinham todos os dias. "Mas é uma Loucura gostosa" disse ele com os olhos aparen- temente cansados e afirmou não ter mais físico para isso. Joseano contou que as crianças perguntavam para ele onde estavam os brincos e se ele havia cortado o cabelo. Perguntavam isso, pois, na creche, só tinha mulheres. [...]

Todos pedem uma canção. Joseano dedilha as cordas do violão, e com o vento tocando nossa pele e uma sensação de paz ele canta "EU E A BRISA". A professora Laura deita no chão e muitos sorrisos vêm à tona, acho que porque é muito difícil ver um professor tão à vontade na frente de seus alunos (acho que é por que às vezes vemos um professor como um deus, que é inalcançável para nós mortais). [...]

Momento de silêncio... A professora Laura pergunta se estávamos tímidos. Letícia disse que estávamos sentindo o momento (e aí pensei com os meus botões: para cada um esse momento foi único $e$ diferente). Para relaxar mais um pouco mais uma música tocada por nosso cravo (flor) "AS ROSAS NÃO FALAM".

[...] começamos a ver as fotografias que cada um havia levado. (Foi nesse momento que parei de escrever tudo. Pois não tinha como ficar registrando em meio a tantas histórias diferentes e emocionantes). A partir daí nos conhecemos 
para além da universidade, nos conhecemos e reconhecemos como filhos, pais, netos, amigos.

Descobrimos muita coisa em comum e distinta, em nossas histórias [...]. (Caderno coletivo. Dani. Registro 21/08/2012; grifos meus).

Considero que a escrita de Dani mostra as sensações vividas e a proposta que estávamos construindo nesse momento. Talvez a questão posta por Dani nos mostre de que forma o contexto escolar ou universitário, a relação professor-aluno e os papéis sociais que ocupamos nessa relação nos fazem esquecer que também somos mais do que professores ou alunos, também somos "filhos, pais, netos, amigos".

E o que significaria esquecer desses outros papéis dentro do contexto escolar?

\section{APÓSO ENCONTRO NO BAMBUZAL...}

Após o encontro, como já explicitado, cada um fez a escrita semanal atrelada às perguntas: $O$ que vês? $O$ que pensas? 0 que fazes com o que pensas? Socializo alguns dos escritos para, a partir deles, refletir sobre quais contribuições os alunos trazem para pensar numa determinada concepção de formação.

Escolhemos o lugar ideal para nosso piquenique acadêmico: à sombra de um bambuzal do campo de futebol da universidade! Um local tranquilo, quietinho, onde batia uma brisa refrescante, propício para nosso lanche, nossas conversas e nossas músicas. [...] Aprendi a ouvir, a prestar atenção no outro que me fala, a valorizar a vida - e também a minha vida - a sentir a existência, $e$ não apenas existir.

Nesses encontros em que é possivel relaxar e sentir o ser humano com tudo o que ele é, eu me refaço como pessoa e também como futura professora, para deixar que a própria vida ensine aquilo que é de maior valor e que está em falta na sociedade atual: o amor ao próximo. (Bruna; grifos meus).

Hoje foi nosso primeiro encontro no campo: ao ar livre, sem as demarcações físicas do espaço regular acadêmico... [...]. Com certeza deste encontro não posso relatar outra coisa senão a paz que deste momento surgiu, pelo encontro de pessoas queridas ao toque suave do vento, ao som de uma bela e calma música, além do contato mágico com a natureza... Além é claro do modo como ali compartilhamos segredos, passados, amores e histórias... Tudo isso nos transforma a cada dia... Transforma colegas em amigos, possíveis 'pré-conceitos' em admiração e vontade de conhecer mais e mais de cada um que está ali, sentado conosco, dividindo também 
suas emoções e sua vida. Não só conversamos, mas dialogamos. Não só olhamos, mas agora observamos. Não só convivemos, mas sim estamos vivendo cada momento dos nossos encontros semanais...

Obrigada grupo por momentos como este, tão sublime... (Helen; grifos meus).

$O$ encontro de hoje, como eu já esperava, foi maravilhoso! Fazia muito tempo que eu não sentava na grama, sentindo o vento no rosto ao som de uma boa música, e me permitindo esquecer de tudo por alguns instantes. Coisas simples assim me encantam!

Me encantou também conhecer um pouco mais sobre a vida de cada um, e poder contar sobre a minha. Esse tipo de movimento nos dá ainda mais afinidade, pois nas nossas reuniões, por mais que conversemos sobre várias coisas, nosso foco é sempre um texto ou algo teórico, mas hoje nós fomos o foco, e ao dividir nossas histórias nos tornamos ainda mais íntimos. (Juliane; grifos meus).

Em meio à grama, sentindo o cheirinho da terra, o farfalhar das folhas, o vento tocando o meu rosto, a imagem do sorriso dos colegas, as lágrimas trazidas pelas lembranças, saudades, amores, o companheirismo, a união; o canto dos passarinhos, os estalos do bambu, os acordes de um vilão, o Jô que tocava ao meu lado, mas de repente estava longe, pois eu voava em meus pensamentos distantes...

O sabor de todas as sensações, o sabor do piquenique, o sabor da cumplicidade. Essa reunião me fez mergulhar, no universo das sensações, em minha própria vida, mergulhei na existência de cada um, cheguei mais pertinho do cada um é, e não simplesmente do que aparentam ser. Isso tudo estreitam nossos laços de convivência, deixamos de ser apenas colegas de um projeto de extensão para sermos cúmplices uns dos outros, para sentirmos juntos.

Tudo isso me faz pensar o quanto é possível deixar as sensações vivas na escola, quebrar essa educação auditiva, expectadora, trazer novas formas de sentir... Cheirar, saborear, tocar, ver, fazer, falar, gritar, cantar, dançar, tudo isso é possível, tudo isso é necessário, porque isso tudo é nossa vida, nosso universo de sensações que nos cercam dentro $e$ fora da escola. (Letícia; grifos meus).

Se nossos encontros já eram uma delícia, imagina ao ar livre, sentados na grama sentindo o vento e fazendo um piquenique... De alguma forma parece que me aproximei ainda mais do grupo, também 
pelo tema tratado que foram fotos e histórias de cada um; mas alguma coisa ali, naquele lugar e naquela forma de estarmos juntos trouxe uma sensação de maior proximidade. [...]. (Marcela; grifos meus).

[...] É lindo saber um pouco mais dos outros. Conhecer os medos, os receios, as vitórias, os enfrentamentos e a coragem que cada um teve que enfrentar até chegar onde estamos. $E$ quantas histórias mais cada um de nós vivemos? E o quanto nos enriqueceria sabermos mais $e$ mais de todos que nos cercam? É a vida sensível. É o ato sensível que se quebra neste mundo capitalizado, homogeneizado, engessado e irrompível. (Raquel; grifos meus).

As considerações dos alunos dizem da importância da constituição de um espaço que possibilita conhecer o outro, estarmos sensíveis, criar certa intimidade e cumplicidade com o outro, aprender a escutar e a dialogar.

\section{QUE FORMAÇÃO É ESSA?}

De todas as considerações apresentadas até aqui me pergunto, como professora formadora de futuros professores, o que ficou para todos nós daquela vivência? O que ficou para mim de todas essas falas? O que elas indiciam? Como considerado por Freire (2001, p. 109), "o espaço pedagógico é um texto para ser constantemente 'lido', interpretado, 'escrito' e 'reescrito'". O que fala o texto escrito a partir do espaço pedagógico constituído no contexto do bambuzal?

Para responder essa pergunta, explicito alguns princípios que considero importantes para considerarmos no processo de formação inicial. A escolha dos princípios surgiu a partir das relações estabelecidas no encontro com meus alunos, foi com eles que aprendi e legitimei crenças e concepções que guardam relação com a necessidade de exercitar certos valores no contexto da formação inicial: o exercício do diálogo, o exercício da escuta, o exercício do trabalho coletivo, o exercício da autonomia.

As falas dos alunos sinalizam a questão do diálogo (BAKHTIN, 2003; FREIRE, 1973) como aspectos fundantes da formação. Isso porque, como apontado por Helen, "não só conversamos, mas dialogamos. Não só olhamos, mas agora observamos. Não só convivemos, mas sim estamos vivendo cada momento dos nossos encontros semanais...".

A questão de pensar na importância do encontro e do outro no processo formativo guarda relação com as considerações de Freire (1973) para quem a busca pelo "ser mais" não se realiza no isolamento, no individualismo, a busca pelo "ser mais" é possível na comunhão, na solidariedade entre os que existem. Assim, é na comunhão e na solidariedade dos que se encontram que é possível o diálogo. Para o autor, a nossa existência como humanos, não pode ser muda nem silenciosa, a nossa existência tem que se nutrir de palavras verdadeiras 
com as quais podemos transformar o mundo.

Lembro que Bakhtin (2003) diz que, quando não há palavras, não pode haver relação dialógica, explicitando que a relação dialógica é uma relação de sentido e que se estabelece no contexto da comunicação verbal. E, como considerado por Kramer (2003), o que configura a nossa humanidade é exatamente o fato de sermos sujeitos sociais, cidadãos ativos na história, mergulhados na e fazedores da cultura, prenhes de tradição, de valores, de desejos, de sonhos, possuidores e produtores de linguagem: "linguagem que é central na constituição de um sujeito social político histórico, linguagem que confere humanidade ao ser humano, que lhe permite exercer essa humanidade" (KRAMER, 2003, p. 11).

Outras questões podem ser apontadas a partir do encontro no bambuzal. Uma delas é importância da escuta, como considerado por Bruna: "aprendi a ouvir, a prestar atenção no outro que me fala, a valorizar a vida-e também a minha vida - a sentir a existência, e não apenas existir". É Freire (2001) que sinaliza que um dos saberes fundamentais do professor é o saber escutar. Como considerado por ele se

[...] o sonho que nos anima é democrático e solidário, não é falando aos outros, de cima para baixo, sobretudo, como se fossemos os portadores da verdade a ser transmitida aos demais, que aprendemos a escutar, mas é escutando que aprendemos a falar com eles. Somente quem escuta paciente e criticamente o outro, fala com ele. (FREIRE, 2001, p. 127).

Penso na aprendizagem da escuta de todos aqueles que estamos envolvidos em processos formativos. Segundo Freire (2001), só quem considera a formação integral do ser humano é que pode perceber essa necessidade de escutar para falar com ele. Quem está preocupado por uma formação atrelada ao treino, fortalece uma forma de falar de cima para baixo, autoritária. O nosso lugar como professores é o de motivar e desafiar a quem escuta no sentido de que aquele que escuta diga, fale, responda, seja um sujeito de enunciação.

Freire $(2001$, p. 135$)$ coloca a necessidade de "escutar o educando em suas dúvidas, em seus receios, em sua incompetência provisória" já que, ao escutá-lo, aprendemos a falar com ele.

O que Freire (2001, p. 135) entende por escutar? Para ele é a

[...] disponibilidade permanente por parte do sujeito que escuta para a abertura à fala do outro, ao gesto do outro, à diferença do outro. A verdadeira escuta não implica abrir mão do direito de discordar, pelo contrário é "escutando bem que me preparo para melhor me colocar ou melhor me situar do ponto de vista das idéias.

Dialogo com Ponzio (2010), que, de uma perspectiva bakhtiniana, explicita a necessidade de nos colocarmos na 
"posição de escuta". Segundo o autor, escutar significa "deixar tempo ao outro" (PONZIO, 2010, p. 26).

Esses autores me permitem legitimar a importância do exercício da escuta nos processos formativos, um exercício que requer tempo, disponibilidade e abertura para estar atento ao outro...

Ainda com a escuta, trago aqui as considerações da Letícia porque, nesse encontro, ela percebeu "o quanto é possível deixar as sensações vivas na escola", ou melhor, em qualquer escola/ universidade. Mas, por outro lado, ela considera a necessidade de "quebrar essa educação auditiva, expectado$r a^{\prime \prime}$, ou seja, enxerga a necessidade de abandonar uma concepção de educação bancária, aquela educação que, nas suas bases, desconsidera a escuta segundo as concepções de Freire e de Ponzio. Letícia nos faz pensar para além do nosso encontro no bambuzal, que educação é essa que vivemos na escola e na universidade? Como fazer para efetivamente deixar tempo ao outro?

Por fim, uma das questões que acredito que tenha marcado o encontro no bambuzal foram as considerações dos alunos em relação à intimidade, à cumplicidade. Como considerado nas escritas:

[...] a partir daí nos conhecemos para além da universidade, nos conhecemos e reconhecemos como filhos, pais, netos, amigos. (Dani).

[...] compartilhamos segredos, passados, amores e histórias... (Helen).
[...] mas hoje nós fomos o foco, e ao dividir nossas histórias nos tornamos ainda mais íntimos. (Juliane).

[...] isso tudo estreitam nossos laços de convivência, deixamos de ser apenas colegas de um projeto de extensão para sermos cúmplices uns dos outros, para sentirmos juntos. (Letícia).

[...] de alguma forma parece que me aproximei ainda mais do grupo, também pelo tema tratado que foram fotos e histórias de cada um... (Marcela).

Penso que o nosso trabalho docente está atravessado/marcado pelo tipo de relações que instituímos com nossos alunos. A partir daquele encontro no bambuzal, ficou evidente a questão da nossa intimidade. Mas o que significaria intimidade dentro daquele contexto de formação?

Essa foi uma questão que, a partir do segundo semestre do ano de 2012, nos acompanhou nas discussões: a intimidade que temos construído e que tem permitido a construção da confiança para dizer o que pensamos e sentimos. Ainda que, por momentos, nos questionemos se efetivamos tudo o que pensamos e sentimos é posto na roda, a sensação de intimidade e cumplicidade existe!

Dialogo com Teixeira (1996), já que a autora argumenta e outorga sentidos à concepção de intimidade no contexto educativo. Enfatiza que essa relação de intimidade está dada pelo gesto e a 
palavra que não podem estar planejadas/programadas. Uma intimidade que pode ser percebida na espontaneidade de acontecimentos vividos no cotidiano de forma corriqueira, na qual palavras e gestos têm a possibilidade de aparecer mais soltos. Uma intimidade que vai "enredando o professor e aluno numa convivência impregnada de calor humano, de sentimentos, e não apenas estabelecida em funções e papéis sociais" (TEIXEIRA, 1996, p. 188). Segundo a mesma autora:

$\mathrm{Na}$ verdade, a proximidade e convivência cotidiana faz surgir uma certa liberdade e acolhimento mútuo entre professores e alunos. Há momentos em que as teias e tons de suas relações extrapolam os conteúdos e normas escolares, escapando aos figurinos e regulamentação. Nesse sentido, sua convivência caracteriza-se também por uma certa imprevisibilidade. Nem sempre uma aula é o que dela se espera... Nem sempre é possível cumprir tudo o que estava programado... Alunos e professores podem surpreender-se uns aos outros... (TEIXEIRA, 1996, p. 188).

Talvez o encontro no bambuzal tenha nos surpreendido..., pela coragem de socializar nossas histórias, por mostrar e expor sentimentos profundos, por mostrar nossa sensibilidade, porque a intimidade esteve presente, porque foi possível deixar "as sensações vivas", " $a$ vida sensível".

\section{QUE PEDAGOGIA É ESSA?}

Lembro que essa proposta foi realizada com futuros professores. Interessa aqui evidenciar que uma formação atenta ao outro, que promova o diálogo, a autonomia, o trabalho coletivo, precisa de uma prática pedagógica para além dos discursos. Nesse sentido, me questiono: "como ensinar um saber que não diga o que fazer?". Que não diga de forma padronizada. Que não diga de forma sistematizada. Que não indique passos a seguir nem procedimentos a considerar. Que não seja um receituário, um manual. Que não explique, que não enquadre. Trata-se de um saber que não admite esses processos.

Penso que é um saber que pode ser aprendido a partir do vivido, do experienciado, do exercício de...

Quando Contreras Domingo (2010) discute a ideia da pedagogia da experiência, faz uma problematização a partir de duas frentes. Por um lado, questiona qual o saber pedagógico que para ele, enquanto formador de futuros professores, Ihe permitiriam orientar sua tarefa. Segundo o autor, ele não precisa, como formador, de um saber que sirva só para "aplicar na prática". Ele procura um saber que, partindo daquilo que vivemos, possa iluminar questões acerca de nós mesmos, dos outros e de nossa relação. Ou seja, é um saber que não impossibilita viver experiências. Um saber que não nos responde quem somos e a que podemos aspirar, mas nos situa nessas questões como um modo de viver em relação. 
O autor também está preocupado com entender quais os saberes que os estudantes, futuros professores, necessitam para desenvolver sua tarefa, entendendo tarefa como a busca do "encontro intencional", mas não determinado com seus futuros alunos, ou seja, trata-se de um saber que destaque a importância de olhar para as relações que instituímos com nossos alunos no contexto escolar. $\mathrm{O}$ autor se questiona o que é que possibilita que nossos alunos e alunas tenham força, sentido de si mesmo, abertura, imaginação, conexão, reconhecimento, confiança, decisão, segurança e flexibilidade? Segundo ele, a pedagogia da experiência, como pedagogia da singularidade, da alteridade, da conversação e da escuta, conta com tudo isso e ainda questiona tudo isso.

A seguir trago a escrita que fiz após o encontro no bambuzal, destacando uma questão que me inquietava, o que é que fazemos quando estamos juntos... Talvez esse acontecimento possa mostrar quais são esses saberes que eu como professora formadora aprendo a partir da experiência, nesse encontro intencional com meus alunos:

[...] Só queria dizer que por momentos me senti fora da água, esquisito estar com vocês em outro espaço que não na sala de aula, não estou falando que não gostei, mas só dizer de alguma sensação no começo do encontro. $O$ que é que estou fazendo lá com eles? O que é que estamos fazendo juntos? Uma pergunta que intento responder não por termos mudado de espaço e sim para entender o que faz, para além das bolsas e do projeto termos a firmeza de dar continuidade a estar juntos: que objetivos nos unem? Que diferenças nos unem? Que preocupações nos unem? O que nos entrelaça? $O$ que é que nos enlaça? O que é que nos costura...

Música, comida, vento, folhas, fotos, caras, falas.

FALAS.

O que permite tanta exposição, tanta sinceridade e franqueza, tanto "olha este", "este sou eu" e "isso é minha vida ou parte dela".[...]

Sempre nós [nos encontro do projeto de extensão] falamos dos outros, daquele aluno que tem um irmão..., daquela familia que separou, daquele aluno imigrante..., daquela que não tem pai, daquele que tem problemas com... E de repente, todos aqueles outros dos quais falamos, somos nós! Os outros dos quais sempre falamos também tem a ver com nós. Aí percebi com emoção que nós somos os outros, e que talvez esse movimento de enxergar para os outros seja necessário olhar para nós, e temos feito isso no último encontro. (Laura, 21/08/2012). 
Diante da minha inquietação de pensar o que é que fazemos juntos no projeto de extensão, a Raquel enviou uma mensagem para todos explicitando o que ela considerava que fazíamos juntos.

Como eu disse em minha escrita: nosso grupo tem algo peculiar - conseguimos trabaIhar em conjunto sem termos esta hierarquia/autoridade.

\section{0 que fazemos juntos?}

- Acolhemos um ao outro em uma dificuldade.

- Sugerimos possibilidades.

- Crescemos com as experiências explicitadas.

- Nos enriquecemos com as pesquisas realizadas.

- Nos reconstruímos como pessoas.

- Absorvemos através de processo do fazer/ser um profissional de qualidade.

- Desabafamos.

- Evoluímos.

- Nos resgatamos nesse processo de re-humanização.

- Quebramos e rompemos com paradigmas.

- Aprendemos a superar desafios.

- Vemos as possibilidades através das leituras realizadas $e$ que embasam nossa expectativa diante da Escola, e nossas experiência [...]

Talvez por estarmos "livres" das paredes que diariamente nos cercam, pode ter te provocado a sensação de que nada foi direcionado e que o "controle" (que nos cerca) foi perdido... Mas eu vejo esta experiência como um rompimento do clássico, da rotina, daquela coisa que nos prende. Estar ao ar livre nos possibilitou sentir mais, ver mais, nos conhecermos meIhor e a experienciar situações/ sentimentos diferentes...!

E será que eu ensinei esses saberes? Talvez os saberes aprendidos nesses encontros tenham a ver com pensar na "pedagogia da experiência" sustentada por Contreras, uma vez que é no encontro com os outros que vamos aprendendo saberes fundamentais na nossa constituição como professores em exercício e professores em formação, saberes que não estão sistematizados e que acredito que podem ser apreendidos na vida compartilhada. Saberes que dizem de uma aposta nos vínculos que estabelecemos no contexto educativo.

\section{ALGUMAS CONSIDERAÇÕES}

Em função da experiência vivida, legitimo a importância do exercício da escuta nos processos formativos, um exercício que requer tempo, disponibilidade e abertura para estar atento ao outro...

Nesse sentido, dialogo com Nóvoa (2009), quem afirma que a formação de professores tem que estar atenta às dimensões pessoais da profissão docente. Ele destaca a importância de trabalhar a capacidade de relação e de comunicação 
que define o tato pedagógico dos professores (e futuros professores). A ênfase na questão da dimensão pessoal fica explícita assim: "Refiro-me à necessidade de elaborar um conhecimento pessoal (um autoconhecimeto) no interior do conhecimento profissional e de captar (de capturar) o sentido de uma profissão que não cabe apenas numa matriz técnica ou científica" (NÓVOA, 2009, p. 39 , destaques meus).

Catani (2006) considera que uma boa educação de professores deveria ter como principal marca uma cultura da atenção. A hipótese da autora é que a escrita autobiográfica, a escrita de si, enquanto exercício sistemático deveria ser um exercício fundante em uma Educação que pretende oferecer espaço para a reinvenção de si, para a reconstrução de trajetórias de vida e Educação. Nesse sentido, importa considerar essas escritas como base para construir e reconstruir a nossa ação no contexto educativo.

Para Catani (2006, p. 83), uma cultura da atenção, inclui formas de reconhecimento de si mesmo e dos outros e, além disso, precisa ser "geradora de atitudes mediante as quais se ausculta a realidade, se olha para ver o outro, se observa a si próprio como sujeito/objeto de conhecimento". Considero que se trata de uma perspectiva que implica valorizar, nos processos de formação de futuros professores, questões científicas ou didático-pedagógicas, mas também reconhecer a atenção que merecem os "sentimentos e relações que os sujeitos constroem para sua inserção na realidade" (CATANI, 2006, p. 83).

Como fazer propostas que promovam essa dimensão pessoal, se pensamos na constituição de um professor atento ao outro, que reconheça a alteridade, que promova vínculos de confiança com os alunos, enfim que reconheça o tato pedagógico?

E o que o exercício do diálogo, da escuta e da intimidade tem a ver com a qualidade nos processos formativos? A seguir algumas pistas que me ajudam a compreender de que qualidade estamos falando, por exemplo, quando fazemos propostas dessa natureza.

Quais são então os significados da palavra qualidade dentro do contexto político desses anos? De que se fala quando se fala em qualidade? Silva (2009) discute a qualidade social da educação e questiona de que forma os governos e gestores priorizam os critérios econômicos para atribuir qualidade à educação e "desconsideram os limites e as imperfeições geradas pelo mercado e sua incapacidade para corrigir questões sociais, que costumam se agravar quando deixadas à mercê dos interesses do capital financeiro e de empresários" (SILVA, 2009, p. 223).

Segundo a autora, "a qualidade social na educação não se restringe a fórmulas matemáticas, tampouco a resultados estabelecidos a priori e a medidas lineares descontextualizadas" (SILVA, 2009, p. 223). A partir dessas 
considerações, a autora mostra de que forma alguns fatores internos e externos à escola se refletem na qualidade da educação escolar com o objetivo de apresentar elementos indicadores de qualidade social na educação. Ainda que a autora faça referência à escola de educação básica, penso que suas considerações são importantes para pensar também na qualidade social da educação na universidade.

A partir de Silva (2009), destaco alguns elementos que sinalizam a qualidade social da educação e que estão diretamente vinculados com este trabaIho: a organização do trabalho pedagógico; os projetos escolares; o ambiente saudável; o respeito às diferenças e o diálogo como premissa básica; o trabaIho colaborativo.

Penso que a proposta no bambuzal foi um projeto que foi se delineando a partir das necessidades do grupo (como deixado em evidência pelos registros produzidos pelos graduandos), foi o grupo que, a partir das discussões do primeiro semestre de 2012, mostrou a necessidade de, no contexto universitário, mostrar os "seus segredos do coração". Foi o grupo que sentiu a necessidade de ocupar outros espaços da universidade para sentar juntos, escutar as nossas próprias histórias e descobrir quem é o outro - o colega, a professora.

Estar juntos no bambuzal deu a dimensão de todos os valores que já tínhamos construído nesses anos, legitimando assim o exercício do diálogo, o exercício do fazer coletivo. Penso que, nos encontros semanais do projeto de extensão, o "ambiente saudável" já estava configurado a partir da confiança e do respeito pelas nossas diferenças, mas na experiência realizada no bambuzal o "ambiente saudável" que constituímos mostrou a possibilidade de aprofundar a nossa intimidade.

Talvez criar um "ambiente saudável" no contexto da universidade também tenha a ver com a consideração de Freire (2001) ao dizer da falsa separação entre seriedade docente e afetividade. Segundo o mesmo autor, a afetividade não está desvinculada da cognoscibilidade. E ainda considera que é falso acreditar que seriedade docente e alegria são inconciliáveis, porque, quanto mais rigorosos nos tornamos na nossa busca e na nossa docência, mais alegres e esperançosos estamos: "a alegria não chega apenas no encontro do achado, mas faz parte do processo de busca. Ensinar e aprender não pode dar-se fora da procura, fora da boniteza e da alegria" (FREIRE, 2001, p. 160). Para o autor, a prática educativa está atravessada pela afetividade, alegria, capacidade científica, domínio técnico e deveria estar a serviço da mudança.

A partir das problematizações elencadas até aqui, considero que a proposta de formação articulada ao projeto de extensão mostra a importância de resgatar a humanidade nos processos formativos, pois talvez seja esta a qualidade de educação que almejamos. 


\section{REFERÊNCIAS}

AMORIM, Marília. O pesquisador e seu outro: Bakhtin nas ciências humanas. São Paulo: Musa Editora, 2004.

BAKHTIN, Mikhail. Estética da criação verbal. São Paulo: Martins Fontes, 2003.

CAMPOS, Cristina M.; PRADO, Guilherme do Val Toledo (Org.). Pipocas pedagógicas: narrativas outras da escola. São Carlos, SP: Pedro \& João, 2013.

CATANI, Denise B. A autobiografia como saber e a educação como invenção de si. In: SOUZA, E. C. de; ABRAHÃO, M. H. M. B. (Org.). Tempos, narrativas e ficções: a invenção de si. Porto Alegre, RS: EDIPUCRS, 2006.

CHALUH, Laura Noemi. Formação inicial de professores: grupo, diálogo e trabalho coletivo. In: CONGRESSO ESTADUAL PAULISTA SOBRE FORMAÇÃO DE EDUCADORES, 11.; CONGRESSO NACIONAL DE FORMAÇÃO DE PROFESSORES, 1., 2011, Águas de Lindóia, SP. Anais... São Paulo: UNESP; PROGRAD, 2011a. p. 972-983.

. Futuros professores: um processo coletivo de formação. In: GRUPO DE ESTUDOS DOS GÊNEROS DO DISCURSO [GEGe]. Questões de cultura e contemporaneidade: o olhar oblíquo de Bakhtin. São Carlos, SP: Pedro \& João Editores, 2011b. p. 161-174.

. Percursos na formação inicial de professores. In: CHALUH, L. N. (Org.). Escolauniversidade: olhares e encontros na formação de professores. São Carlos, SP: Pedro \& João Editores, 2012.

CONTRERAS DOMINGO, José. Pedagogías de la experiencia y la experiencia de la pedagogía. In: CONTRERAS DOMINGO, José; PÉREZ DE LARA FERRÉ, N. (Comp.). Investigar la experiencia educativa. Madrid: Ediciones Morata, 2010.

FOX, Mem. Guilherme Augusto Araújo Fernandes. São Paulo: Brinque Books, 1995.

FREIRE, Paulo. Pedagogia da autonomia: saberes necessários à prática educativa. 17. ed. São Paulo: Paz e Terra, 2001.

FREIRE, Paulo. Pedagogía del oprimido. Tradução de Jorge Mellado. 7. ed. Buenos Aires: Siglo Veintinuno Argentina Editores, 1973.

FREITAS, Maria Teresa. A perspectiva sócio-histórica: uma visão humana da construção do conhecimento. In: FREITAS, Maria Teresa; JOBIM e SOUZA, Solange; KRAMER, Sonia. (Org.). Ciências humanas e pesquisa: leitura de Mikhail Bakhtin. São Paulo: Cortez, 2003. p. 26-38. (Coleção questões da nossa época; v. 107).

KOLB-BERNARDES, Rosvita. Segredos do coração: a escola como espaço para o olhar sensível. Cadernos CEDES, Campinas, SP, v. 30, n. 80, p. 72-83, 2010.

KRAMER, Sonia. Por entre as pedras: arma e sonho na escola. 3. ed., 3. impr. São Paulo: Ática, 2003. 
NÓVOA, Antonio. Professores: imagens do futuro presente. Lisboa: Educa, 2009.

PONZIO, Augusto. Procurando uma palavra outra. São Carlos, SP: Pedro \& João Editores, 2010.

RANCIÈRE, Jacques. O mestre ignorante: cinco lições sobre a emancipação intelectual. Belo Horizonte: Autêntica, 2002.

SILVA, Maria Abádia da. Qualidade social da educação pública: algumas aproximações. Caderno CEDES [online], Campinas, SP, v. 29, n. 78, p. 216-226, 2009.

TEIXEIRA, Inês Assunção de Castro. Os professores como sujeitos sócio-culturais. In: DAYRELL, Juarez T. (Org.). Múltiplos olhares sobre educação e cultura. Belo Horizonte: UFMG, 1996.

\section{Sobre a autora:}

Laura Noemi Chaluh: Doutora em Educação pela Universidade Estadual de Campinas. Professora do Departamento de Educação, área de Didática e do Programa de Pós-Graduação em Educação do Instituto de Biociências da UNESP/Rio Claro. E-mail: Ichaluh@rc.unesp.br

\section{Recebido em maio de 2016}

\section{Aprovado para publicação em novembro de 2016.}

